\title{
Turkish Moral Metacognition Scale (TMMS): The Study of Adaptation, Validation and Reliability
}

\section{Research Article}

\section{Umit DURUK ${ }^{1}$, Esra ACIKGUL FIRAT ${ }^{2}$, Abuzer AKGUN ${ }^{3}$}

${ }_{1}^{1}$ Adiyaman University, Faculty of Education, Department of Mathematics and Science Education, Turkey, ORCID: 0000-0002-9079-9367

${ }^{2}$ Adiyaman University, Faculty of Education, Department of Mathematics and Science Education, Turkey, ORCID: 0000-0002-6401-1476

${ }^{3}$ Adiyaman University, Faculty of Education, Department of Mathematics and Science Education, Turkey, ORCID: 0000-0002-3966-4483

To cite this article: Duruk, U., Firat, E. A., \& Akgun, A. (2020). Turkish Moral Metacognition Scale (TMMS): The Study of Adaptation, Validation and Reliability, International Online Journal of Educational Sciences, 12(3), 153-163.

\begin{tabular}{l} 
ARTICLE INF \\
\hline Article History: \\
Received: 13.12 .2019 \\
Available online: \\
07.07 .2020
\end{tabular}

Corresponding author's address: Adıyaman University, Turkey

Telephone: +95059945931

e-mail: eacikgul@adiyaman.edu.tr

DOI: https://doi.org/10.15345/iojes.2020.03.012

Keywords:

\begin{abstract}
Metacognition is an invaluable agent in ethical decision-making process. This is because it gives individuals the opportunity to switch gears through the monitoring and control of thinking in solving complex ethical dilemmas. It can be said that the importance of studies evaluating the decision-making process from a moral point of view increases considering the necessity of taking a huge number of decisions in today's complex world. However, studies that measure metacognition as a domain-specific capacity are rarely encountered. The purpose of the present study, then, was to adapt the moral metacognition scale developed in English by McMahon and Good (2016) into Turkish language and to evaluate dimensionality of the scale. The study participants consisted of 302 prospective teachers. This study is a scale adaptation study performed in line with the survey method. The psychometric properties of the instrument have been established by the use of confirmatory factor analysis. Cronbach's alpha coefficient was used to determine the internal consistency of each of the confirmed factors. Data collected from the sample were tested for sampling adequacy. KMO value was found .85 as meritorious and Bartlett test that examines homogeneity of variances was significant. To validate the scale, we ran a four-factor confirmatory factor analysis using chi-square statistic $(\chi 2 / \mathrm{df}=1.33 ; \mathrm{RMSEA}=0.045 ; \mathrm{SRMR}=0.063 ; \mathrm{RMR}=0.059 ; \mathrm{CFI}=0.97 ; \mathrm{GFI}=0,89)$. Given these values, it was seen that scale's hypothesized measurement model with four factors was consistent with actual data yielding good fit indices. In addition, the overall internal reliability of the scale was found to be .87 and $.75, .72, .56, .74$ for the dimensions in the scale, respectively. The results showed that the scale met the validity and reliability. In conclusion, Turkish version of the moral metacognition scale provided a valid and reliable measure of moral metacognition across preservice teachers.
\end{abstract}

(C) 2020 IOJES. All rights reserved

Moral learning, ethical decision-making, moral metacognition, scale adaptation 


\section{Introduction}

It becomes questionable whether the decisions we make in line with our habits, which often guide our daily lives and are often performed in an unconscious manner, are informed. This situation has become a more prominent problem in our daily life, which has been going through a rapid dynamism and change especially in the political, economic, social and technological sense. As the researches on current issues became widespread, it was noted that some issues were inherently moral dilemmas and different perspectives on these issues persisted in the light of different perspectives. What is expected of individuals with a contemporary understanding of science is that they make more rational and deliberative decisions by relatively disabling their existing cognitive shortcuts while exhibiting decision-making behavior on an ethical issue. Although moral decision-making models are generally based on the belief that people make their decisions in a rational and deliberate way, recent research findings point out that moral decisions are made in a less deliberate and desirable way, contrary to popular belief (McMahon and Good, 2016). Similarly, individuals who have to make a large number of decisions in a short time within the current intensity of everyday life show greater reliance on cognitive shortcuts in decision-making. Moreover, perhaps very few individuals question the patterns of thinking that prevail in everyday life. Thus, there is a risk of lack of awareness as an important driving force in ethical decision-making. In other words, this reduces the likelihood that individuals' judgements about the events they encounter in daily life will be examined in depth according to ethical criteria and informed decisions will be taken accordingly. The awareness component is important in that it has a leading role in putting metacognition skills into performance for informed decision-making (Schraw \& Dennison, 1994). In addition, individuals should be able to make switch gear in the face of the problems of daily life in line with the intensity of the moral content of that problem. At this stage, metacognition stands out in terms of its ability to control cognition. Moral metacognition means awareness considering the moral reasoning decision-making process on ethical issues, monitoring and control of thinking for deliberate decision-making in the process of ethical reasoning (Narvaez, 2010). Moral metacognition has a key role in moral decision-making process in terms of these features.

When the literature is examined, it is seen that the studies on moral metacognition are very limited in number. In these studies, theoretical justifications regarding the effect of metacognition on moral decisionmaking mechanisms in cognitive-field are presented (Hannah, Avolio, \& May, 2011; Narvaez, 2010). More empirical studies are needed to analyze the complex relationships between moral metacognition and decisionmaking processes, which play a critical role in the decision-making process. Considering the essential role of moral metacognition in ethical decision-making process as a general capacity, the inclusion of metacognition into moral learning would offer insights into the complexities surrounding ethical issues. Therefore, the need for measuring moral metacognition is increasing. This need increases the effect of measuring ethical metacognition. Because, although there are scales related to the metacognition of a complex structure, it is seen that there is not a measurement tool that investigates the role of metacognition in moral decision-making process, to the best of our knowledge. Moreover, a scale that measures ethical metacognition as domainspecific has recently been developed (e.g. McMahon \& Good, 2016). Therefore, a study that directly addresses this problem in relation to moral metacognition is considered necessary. To this end, the purpose of the current study was to adapt domain-specific moral metacognition scale (MMS) into Turkish language and to explore its psychometric properties in addition to assess prospective teachers' level of moral metacognition. In order to continue adapting the MMS tool to measure the level of moral metacognition, a framework should then be established for the structures to be included.

The next section of the study provides the theoretical background articulating aforementioned concepts here. Methodology follows this section, and the study concludes with a discussion of the results for the ethical decision-making literature along with moral metacognition. 


\section{Theoretical Background}

The present study is grounded in the theoretical perspective that moral metacognition is a critical factor in effective ethical decision making (Hannah et al. 2011; Narvaez, 2010; Sadler-Smith, 2012). Consequently, the overall discussion in this section was guided by four related conceptual frameworks: ethical decision-making, moral reasoning, metacognition and moral metacognition.

It is widely noted that behaviors are situated as value-laden. Since morality cannot be independent of value, morality, which has been put into practice, plays an important role in guiding these values in the decision-making process (Aikenhead, 1985). Hence, decision-making is defined as reasoning choices among alternatives based on judgments consistent (Heath, White, Berlin, \& Park, 1987). In other words, decisionmaking is justification of the choice among other alternatives. This reasoned decision includes judgments about the values of the individual (Cassidy and Kurfman, 1977). The ethical dilemmas of increasing dynamism and complexity constitute a paradox. Therefore, it is important to question the ethical aspects of the decisions of individuals who frequently encounter ethical dilemmas in their daily lives.

The reasoning of value-laden behaviors with a rational attitude points to the concept of ethics, also known as li conscious morality, ve which is more universal than morality. Ethics refers to every day's work, decisions we make, we act in accordance with ethical principles while making these decisions and implementing our actions (Oguz, 2001). In conclusion, ethical decision making is a systematic process involving discrete cognitive activities (Trevino, Weaver and Reynolds, 2006). In general, ethical decisionmaking process includes awareness and judgment. Therefore, ethical decision-making requires conscious deliberation on rational / deliberative in this systematic process and consists of certain stages and shaped by the complex interactions between these stages. In the absence of careful deliberation, individuals have to make a large number of decisions. This situation is also related to the moral reasoning of individuals' decisionmaking processes and therefore it can be said that morality triggers a role in ethical decision-making process.

Kohlberg (1963), considered as the father of moral development, defined the concept of morality as cognition and reasoning through cognition. In contrast, individuals tend to be more willing to require judgmental decision-makers to spend conscious cognitive resources, and some individuals seem more voluntary and able to make moral reasoning than others (Hannah et al., 2011). When people need to make judgments about various moral dilemma, they can deliberately analyze the right and wrong aspects of the subject, the possible benefits and harms, and whether the decision is fair or not. Individuals try to simplify processing information to separate cognitive resources and initiate this process in the context of ethical decision making through the implementation of morally relevant schemes (Fiske and Taylor, 1991). In an other description, Rest (1986) posits that in a four-stage model of decision-making on an ethical issue, including awareness, judgment, intention and ethical decision-making, respectively. It is important that the first stage of this model is awareness. Therefore, it can be said that individuals should be at a certain level of awareness in order to make informed decisions about an ethical situation. This awareness is important for organizing the cognitive schemes of individuals before making decisions about ethical situations and making the switch gear for the ethical intensity of the situation. The whole process requires a certain level of self-regulation in both awareness and regulation. Self-regulation enable individuals to be engaged in contextualized thinking on ethical decision contexts including ethical dilemmas more often (Jordan, 2009). Self-regulated learning can be defined as concepts into the learning environment and their regulation (Schraw, Crippen ve Hartley, 2006). More specifically, self-regulation skills play a more critical role in situations where the cognitive burden needed in learning environments increases, based on the ethical intensity involved in the dilemma (Chong, 2007). In addition, individuals who exhibit self-regulating behavior actively participate in their own learning processes taking into account metacognitive processes (Zimmerman, 1989). Metacognitive skills used in metacognitive processes are thought to be useful in cases where the schemes are inadequate during a cognitive 
process (Ricco \& Overton, 2011). Thus, there is consensus that metacognition is a central component of selfregulation processes of individuals (Dinsmore, Alexander, \& Loughlin, 2008; Efklides, 2006; Lajoie, 2008).

Self-regulation, self-regulation-based learning and metacognition are important cornerstones of the cognitive control processes mentioned in a specific order (Schunk, 2008). In today's world, where the classical theories explaining the ethical decision-making process only question the fundamental assumption that rational decisions are made, moral metacognition can be said to be at the intersection of these three main concepts. Moral metacognition is the control of the thinking process produced by the individual who conducts the moral reasoning, through the inquiries such as how he is aware of the process of thinking, how he follows the process, and reflects on it (Narvaez, 2010). More specifically, in order to achieve the ultimate goal of ethical decision making, moral metacognition, as stated in the basic assumptions of classical theories, paves the way for an individual to participate in the decision-making process with a certain awareness of the content and intensity of the dilemma rather than making instant decisions through existing schemes (Hannah et al. (2011).

Particularly in the post-1960 period, due to the diversification of common views on the interactions between learning motivation and academic achievement, cognitive theories that prioritized the impact of environmental factors in the learning process were directed towards factors such as processing, storing and recalling information over time (Schunk, 2008). This has led to an increase in pedagogical-based questions, such as the extent to which instructional orientations of teachers, who are active planners and guides of teaching, are appropriate for cognitive learning and expected instructional outcomes. The individual differences of the students paved the way for the idea that teaching with traditional teaching methods should be revised dynamically according to individual interest, needs and readiness levels. This puts teachers in the position of an active organizer of teaching responsibility for pedagogical planning and continuous monitoring of these needs to meet the specified needs. Teachers especially need metacognitive knowledge and skills during context-specific classroom activities (Zohar and Barzilai, 2013). It can be said that the intensity of today's teaching contents and the subject-oriented content-oriented teaching approach led teachers to think less about the level of ethical compliance of the teaching content and environments and that they had to make more decisions in a short time regarding the situations that could create ethical violations. Therefore, the question of what impact the moral metacognition teacher or prospective teachers have on decision-making processes needs to be examined. Therefore, it is considered important to develop and adapt the measurement tools to measure the moral-metacognition levels of prospective teachers. From this point of view, this study aimed to adapt to Turkish of the "Moral Metacognition Scale" originally developed by McMahon and Good (2016) and to make the validity and reliability studies.

\section{Methodology}

This study includes the adaptation of the "Moral Metacognition Scale" originally developed by McMahon and Good (2016) to Turkish and the validity and reliability studies of the TMMS through employing Confirmatory Factor Analysis (CFA). The CFA allows the researcher to test the hypothesis that there is a relationship between the observed variables and the underlying structures (Suhr, 2006). In this section, information about the study group, data collection tool, adaptation procedure of the scaleand data analysis are further explained and elaborated.

\section{Study Group}

The study participants consisted of 236 prospective teachers studying at Adiyaman University in Turkey. $\% 65(\mathrm{n}=153)$ of the participants were female and \% $35(\mathrm{n}=83)$ were male. 81 of the prospective teachers' are studying in Science Teacher Education, 54 of them are in Arabic Language Teacher Education, 55 are in Elementary School Teacher Education, and 46 are in Psychological Guidance \& Counselling Teacher Education. 


\section{Data Collection Tool}

The original English version of the scale developed by McMahon and Good (2016) was obtained from the article in which the scale was published and permission was obtained from the author to begin translation process of the scale. The original form of the scale consists of 20 items and investigates 4 factors (regulation of cognition, knowledge of cognition (declarative), knowledge of cognition (procedural), and knowledge of cognition (conditional)). The items were scored very strongly disagree (1), strongly disagree (2), somewhat disagree (3), somewhat agree (4), strongly agree (5), and very strongly agree (6). In the development stage of the scale, exploration (Study 1) and confirmation (Study 2) of the factor structure, and the demonstration of convergent (Studies 3 and 4), discriminant (Studies 3 and 4), and predictive (Study 4) validity analysis were performed. The maximum score receivable from the scale was 140, and the minimum score receivable was 76.

\section{Adaptation Procedure}

In the adaptation process, the original scale was first translated to Turkish by 4 experts who have mastered the English language. The form translated into Turkish by the experts was examined by researchers and the draft TMMS was formed. The Turkish language expert evaluated the draft TMMS in terms of linguistic equivalence of test and proposed changes were made. Then, , 4 experts were asked to give points each item in terms of linguistic (usage of words / idioms) and cultural equivalence through the language equivalence expert form. The mean scores of each item were taken and the items with low mean values were reviewed. "I stop and review the elements of an ethical dilemma when I remain unclear" item is an example for this situation. After the revisions, 10 preservice teachers were asked to evaluate each item in terms of clarity. They were also asked to write down what they understood of each item. Some concepts that are understood differently or not understood sufficiently have been changed accordingly. Finally, the Turkish version of the scale was retranslated into English by means of the back translation method and compared with the original scale.

The final scale (TMMS) was applied to 236 prospective science teachers. Data were collected via paperand-pencil administration of the MMS. During the data collection, the scope and purpose of the research were expressed and the contact information were also given to the participants. Participants responded to the scale within 10-15 minutes. Participants reported the levels of participation for each of the items after completing the first part of the scale, which consisted of demographic information questions.

\section{Data Analysis}

The construct validity of the Turkish version of the scale was tested with confirmatory factor analysis (CFA). Confirmatory FA is a more complex technique used in the later stages of the research process to test a theory of latent processes, and variables are carefully and specifically selected to elicit the underlying processes (Tabachnick, Fidell, \& Ullman, 2007). Comparative Fit Indices (x2/df, RMSEA, RMR, SRMR, NFI, NNFI, CFI, GFI, AGFI) was calculated to test the model of the Turkish version of the scale. Furthermore, the Path diagram was drawn and standardized loadings, $R^{2}$ and $t$ values of the items in TMMS were calculated. Lisrel 8.80 program was used in the analysis process via the maximum likelihood estimation method. Then item analysis was performed using independent $t$ test based on mean scores of lower and upper $27 \%$ of groups. Also, Cronbach Alpha and Guttman Split-Half Coefficient values were calculated to determine the reliability of TMMS. Finally correlation coefficients between the factors of TMMS were calculated.

\section{Findings}

In this section, there are findings about the confirmatory factor analysis, reliability analysis and correlation analysis of the Turkish version of scale (TMMS). It is commonly used to confirmatory factor models, such as the path diagram, which presents frames that display hidden variables and circles that represent hidden concepts (Albright and Park, 2009). First, the goodness of fit statistics of four sub- 
dimensional models in the original scale were calculated and second-order path diagrams were produced. The path diagram of the four-dimensional model after the modifications is as in Figure 1.

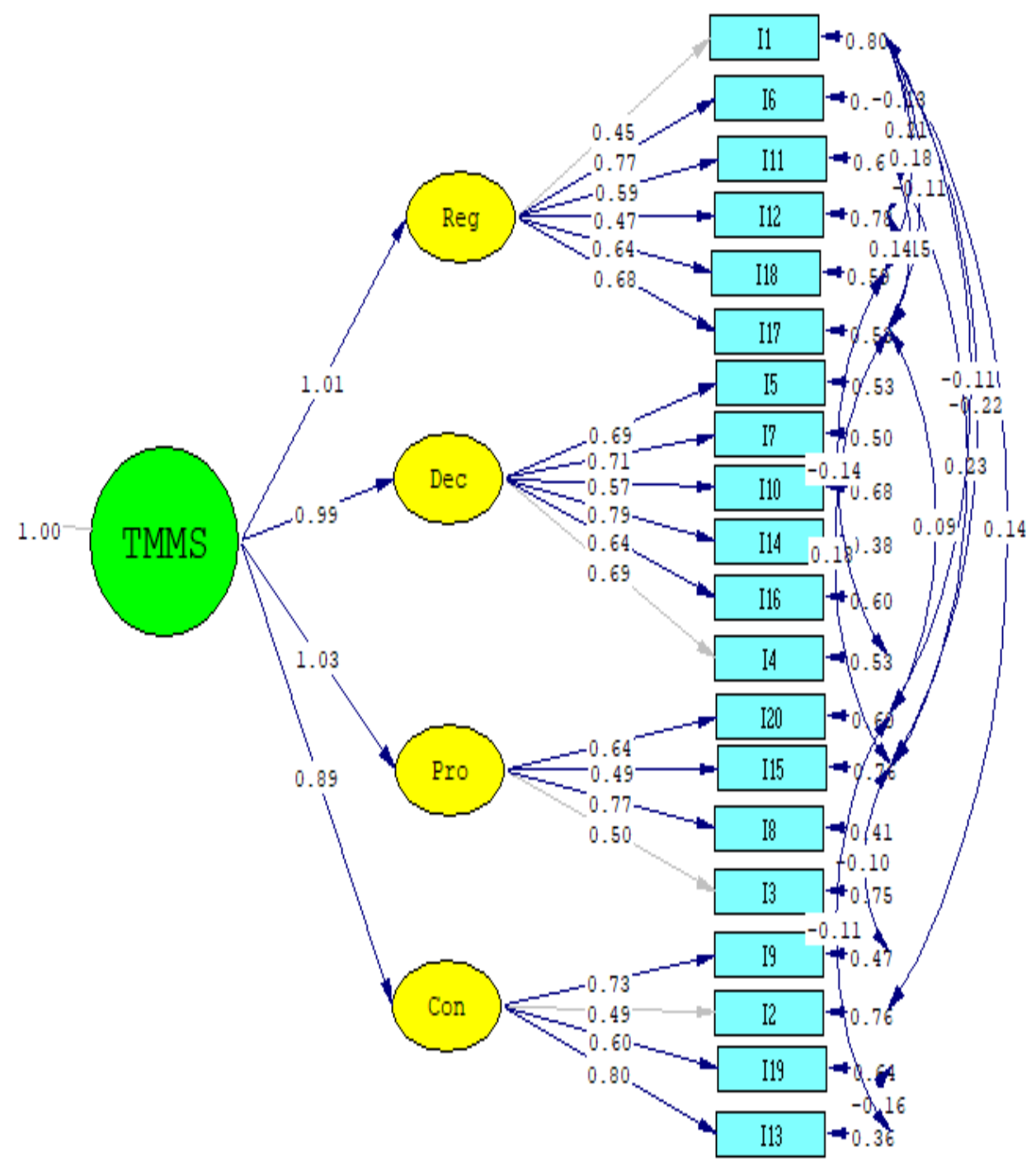

Chi-Square $=222.67, \mathrm{df}=150, \mathrm{P}-\mathrm{value}=0.00011, \mathrm{RMSEA}=0.045$

Figure 1. Path diagram of the model after modification

The fit indices obtained as a result of the second-order confirmatory factor analysis are given in the Table 1.

Table 1. Fit indices of the Turkish TMMS and the standard fit criteria.

\begin{tabular}{llll}
\hline & Good Fit Values & $\begin{array}{l}\text { Acceptable Fit } \\
\text { Values }\end{array}$ & $\begin{array}{l}\text { Turkish TMMS } \\
\text { Fit Indexes }\end{array}$ \\
\hline $\mathrm{x}^{2} / \mathrm{df}$ & $0 \leq \mathrm{x}^{2} / \mathrm{df} \leq 2$ & $2 \leq \mathrm{x}^{2} / \mathrm{df} \leq 3$ & 1.48 \\
$\mathrm{RMSEA}$ & $0 \leq \mathrm{RMSEA} \leq .05$ & $.05 \leq \mathrm{RMSEA} \leq .08$ & $.045(\mathrm{G})$ \\
$\mathrm{RMR}$ & $0 \leq \mathrm{RMR} \leq .05$ & $.05 \leq \mathrm{RMR} \leq .08$ & $.048(\mathrm{G})$ \\
$\mathrm{SRMR}$ & $0 \leq \mathrm{SRMR} \leq .05$ & $0.5 \leq \mathrm{SRMR} \leq .10$ & $.043(\mathrm{G})$ \\
$\mathrm{NFI}$ & $.95 \leq \mathrm{NFI} \leq 1$ & $.90 \leq \mathrm{NFI} \leq .95$ & $.97(\mathrm{G})$ \\
$\mathrm{NNFI}$ & $.97 \leq \mathrm{NNFI} \leq 1$ & $.95 \leq \mathrm{NNFI} \leq .97$ & $.99(\mathrm{G})$
\end{tabular}




\begin{tabular}{llll} 
CFI & $.97 \leq \mathrm{CFI} \leq 1$ & $.95 \leq \mathrm{CFI} \leq .97$ & $.99(\mathrm{G})$ \\
GFI & $.95 \leq \mathrm{GFI} \leq 1$ & $.90 \leq \mathrm{GFI} \leq .95$ & $.91(\mathrm{~A})$ \\
AGFI & $.90 \leq \mathrm{AGFI} \leq 1$ & $.85 \leq \mathrm{AGFI} \leq .90$ & $.88(\mathrm{~A})$ \\
\hline
\end{tabular}

The goodness of fit values in Table 1 were evaluated in terms of the criteria stated by Schermelleh-Engel, Moosbrugger and Müller (2003) and were considered as "good fit values" and "acceptable values". The values in Table 1 are the final goodness of fit indices obtained as a result of the proposed modifications. Table 1 shows that GFI (Goodness of Fit Index) and AGFI (Adjusted Goodness of Fit Index) values are acceptable and other values are good fit values (Schermelleh-Engel et al., 2003). Standardized factor loadings, $t$ values, and $R^{2}$ values obtained from the path analysis are given in Table 2.

Table 2. Standardized loadings, squared standardized loadings, $t$ values of TMMS

\begin{tabular}{lllll}
\hline & & $\begin{array}{l}\text { Standardized } \\
\text { Loadings }\end{array}$ & $\mathbf{R}^{2}$ & t values \\
\hline Regulation of & I1 &, 45 &, 20 & 10,64 \\
Cognition & I6 &, 77 & .59 & 9,38 \\
& I11 & .59 &, 35 & 10,25 \\
& I12 & .47 &, 22 & 10,54 \\
Knowledge of & I17 & .68 &, 47 & 9,87 \\
Cognition & I18 & .63 &, 41 & 10,14 \\
(Declarative) & I4 & .69 &, 44 & 10.10 \\
& I5 &, 69 &, 48 & 9,99 \\
Knowledge of & I7 &, 71 &, 50 & 9,87 \\
Cognition & I10 &, 56 &, 32 & 10,40 \\
(Procedural) & I14 &, 79 &, 62 & 9,14 \\
Knowledge of & I16 &, 63 &, 40 & 10,19 \\
Cognition & I3 &, 50 &, 25 & 10,66 \\
(Conditional) & I8 &, 77 &, 59 & 8,94 \\
& I15 &, 49 &, 24 & 10,63 \\
& I20 &, 63 &, 40 & 10,31 \\
& I2 &, 49 &, 25 & 10,25 \\
& I9 &, 74 &, 53 & 8,59 \\
& I13 &, 81 &, 64 & 8,13 \\
& I19 &, 60 & 10,06 \\
\hline
\end{tabular}

According to the results of second-order confirmatory factor analysis, the standardized loadings of the scale ranged between 0,45-0,81, and t values ranged between 8,13-10,66. Furthermore, item-total correlations were calculated for each item in the final form of the scale and the significance of the difference between item scores of the upper $27 \%$ and lower $27 \%$ groups was determined by using independent t-test, and Cohen $\mathrm{d}$ values were calculated to determine effect sizes.

Table 3. Item Analysis Results Based on Mean Scores of Lower and Upper 27\% of Groups and Reliability Analysis

\begin{tabular}{|c|c|c|c|c|c|c|c|}
\hline \multirow[b]{2}{*}{ Factors } & \multirow[b]{2}{*}{ Items } & \multirow{2}{*}{$\begin{array}{l}\text { Item-Total } \\
\text { Correlations } \\
(n=236)\end{array}$} & \multicolumn{3}{|c|}{$X\left(n_{1,2}=67\right)$} & \multirow[b]{2}{*}{ p } & \multirow[b]{2}{*}{ d } \\
\hline & & & $\begin{array}{l}\text { Lower } \\
\text { Group }\end{array}$ & $\begin{array}{l}\text { Upper } \\
\text { Group }\end{array}$ & $\mathbf{t}$ & & \\
\hline Regulation of & I1 & 44 & 4,17 & 4,82 & $-4,60$ & ,000 & 0,82 \\
\hline Cognition & I6 & ,74 & 3,28 & 5,30 & $-9,29$ & ,000 & 1,67 \\
\hline
\end{tabular}




\begin{tabular}{llllllll} 
& I11 &, 59 & 4,00 & 5,47 & $-9,74$ &, 000 & 1,73 \\
& I12 &, 49 & 4,01 & 5,34 & $-7,27$ &, 000 & 1,30 \\
& I17 &, 69 & 3,46 & 5,31 & $-12,42$ &, 000 & 2,21 \\
Knowledge of & I18 &, 64 & 3,71 & 5,47 & $-10,98$ &, 000 & 1,97 \\
Cognition & I4 &, 63 & 3,52 & 5,25 & $-9,72$ &, 000 & 1,74 \\
(Declarative) & I5 &, 66 & 3,68 & 5,23 & $-10,42$ &, 000 & 1,86 \\
& I7 &, 67 & 3,49 & 5,20 & $-10,50$ &, 000 & 1,88 \\
& I10 &, 58 & 3,98 & 5,36 & $-8,25$ &, 000 & 1,48 \\
Knowledge of & I14 &, 75 & 3,01 & 5,19 & $-12,07$ &, 000 & 2,15 \\
Cognition & I16 &, 61 & 3,61 & 5,22 & $-8,73$ &, 000 & 1,56 \\
(Procedural) & I3 &, 49 & 4,01 & 5,23 & $-7,55$ &, 000 & 1,34 \\
& I8 &, 76 & 3,17 & 5,39 & $-10,77$ &, 000 & 1,93 \\
Knowledge of & I15 &, 48 & 3,52 & 5,19 & $-11,14$ &, 000 & 2,61 \\
Cognition & I20 &, 61 & 4,07 & 5,79 & $-8,55$ &, 000 & 1,53 \\
(Conditional) & I2 &, 45 & 4,07 & 5,23 & $-6,35$ &, 000 & 1,15 \\
& I9 &, 64 & 3,77 & 5,44 & $-8,79$ &, 000 & 1,57 \\
\hline & I13 &, 68 & 3,47 & 5,46 & $-9,89$ &, 000 & 1,78
\end{tabular}

When Table 3 is examined, according to independent t-test results, $t$ values vary between 4,60 and 12,42, Item-total correlations ranged from 0,44 to 0,75 , In addition, when Cohen d values are examined, it is seen that all items have a "large" effect because of $d \leq 0,2$ means small, 0,2 $<d<0,8$ means medium and $d \geq 0,8$ means large effect size according to Cohen's classification (Cohen, 1988). The correlation values calculated between the sub-dimensions of the scale and, Cronbach Alfa and Guttman Split-Half Reliability Coefficients are given in Table 4.

Table 4. Correlation and reliability coefficients of TMMS and sub-dimensions

\begin{tabular}{|c|c|c|c|c|c|}
\hline & Regulation & Declarative & Procedural & Conditional & TMMS \\
\hline \multicolumn{6}{|l|}{ Regulation Cronbach } \\
\hline $\begin{array}{l}\text { Alfa }=, 797 \\
\text { Guttman Split-Half } \\
\text { Coefficient }=, 825\end{array}$ & 1 &, $776^{* *}$ &, $785^{* *}$ & ,712** &, $919^{* *}$ \\
\hline \multicolumn{6}{|l|}{ Declarative Cronbach } \\
\hline $\begin{array}{l}\text { Alfa }=, 814 \\
\text { Guttman Split-Half } \\
\text { Coefficient }=, 778\end{array}$ &, $776^{* *}$ & 1 &, $790^{* *}$ &, $729^{* *}$ &, $928^{* *}$ \\
\hline Procedural Cronbach & & & & & \\
\hline $\begin{array}{l}\text { Alfa }=, 685 \\
\text { Guttman Split-Half } \\
\text { Coefficient }=, 646\end{array}$ &, $785^{* *}$ &, $790^{* *}$ & 1 & ,654 &, $891^{* *}$ \\
\hline Conditional Cronbach & & & & & \\
\hline $\begin{array}{l}\text { Alfa }=, 727 \\
\text { Guttman Split-Half } \\
\text { Coefficient }=, 799\end{array}$ &, $712^{* *}$ &, $729^{* *}$ & ,654 & 1 &, $849^{* *}$ \\
\hline TMMS & & & & & \\
\hline $\begin{array}{l}\text { Cronbach Alpha }=, 930 \\
\text { Guttman Split-Half } \\
\text { Coefficient }=, 899\end{array}$ &, $919^{* *}$ & $928^{* *}$ &, $891^{* *}$ &, $849^{* *}$ & 1 \\
\hline
\end{tabular}


${ }^{* *} \mathrm{p}<, 01$

When the correlation values between the dimensions were examined, it was seen that the values were between 0,654-0,928 and all of them were statistically significant, As a result of the reliability analyzes, the Cronbach alpha coefficient of the TMMS was 0,930 and Guttman Split-Half Coefficient was 0,899.

\section{Discussion and Conclusion}

In this study, “Moral Metacognition Scale developed by McMahon and Good (2016) was adapted to Turkish, and validity/reliability studies were conducted for prospective teachers. The original fourdimensional structure of the scale was tested by second-order confirmatory factor analysis from the validation study, Doğrulayıcı faktör analizi sonuçlarına göre $\chi 2 / \mathrm{df}=1,48$ olarak hesaplanmıştır, The importance of Chisquare has been reported most frequently in studies, and the smaller the Chi-square, the better the model (Hinkin, 1995), Chi-square test shows the amount of difference between expected and observed covariance matrices (Suhr, 2006), $\chi 2$ / df value less than 2 is an indicator of the perfect fit of the model to the data (Çokluk, Şekercioglu, \& Büyüköztürk, 2018; Schermelleh-Engel et al,, 2003). Therefore, the $\chi 2$ / df value obtained in this study is an indicator that the model is appropriate to the data.

According to the results of path analysis, the RMSEA (Root Mean Square Error of Approximation) value of TMMS was calculated as 0,45. RMSEA is linked to residues in the model and RMSEA takes a value between 0-1 and has a smaller RMSEA value that shows better model fit (Suhr, 2006). In this study, RMSEA value of less than 0,05 indicate that the model was closely compatible with degrees of freedom (Arbuckle, 2005). Furthermore, a cut-off value of close to 0,06 for RMSEA results in lower Type II error rates (with acceptable Type-I error rates) (Hu and Bentler, 1999). Therefore, it can be said that the RMSEA value obtained in this study shows good fit of the model (Arbuckle, 2005; Hu and Bentler, 1999; Schermelleh-Engel et al,, 2003; Suhr, 2006; Tabachnick et al. 2007). When the other values were examined in this study, it was determined that the fit indices were RMR: 0,48; SRMR: 0,43; NFI: 0,97; NNFI: 0,99; CFI: 0,99; GFI: 0,91; AGFI: 0,88, The results suggest that, a cutoff value close to, 95 for CFI, a cutoff value close to ,08 for SRMR, and it is concluded that there is a relatively good agreement between the hypothesized model and the observed data on TMMS (Hu and Bentler, 1999), Kline (2010) also stated that the combination thresholds to achieve "acceptable fit" are CFI $\geq 0,95$ and SRMR $\leq 0,08$, Thus according to the obtained values, it was determined that the four-dimensional structure of the model showed a good fit of TMMS (Çokluk et al,, 2018; Hooper, Coughlan and Mullen, 2008; Hu and Bentler, 1999; Kline, 2010; Schermelleh-Engel et al,, 2003; Suhr, 2006; Tabachnick et al. 2007). Therefore, second-order confirmatory factor analysis showed that the Turkish version of the scale was in accordance with the proposed four-sub-dimensional model of scale.

After the confirmatory factor analysis, item-total correlations were calculated and the significance of the difference between item scores of the upper $27 \%$ and lower $27 \%$ groups was determined by independent $t$ test. In all items, it was determined that there was a significant difference between the scores of the participants in the upper and lower $27 \%$ group and the calculated Cohen d values indicate that this difference was "large" effect (Cohen, 1988). The effect size indicates the standard deviation value of the practical values that differ significantly (Cohen, 1988). As a result of the reliability analyzes, the Cronbach alpha coefficient of the TMMS was 0,930 and Guttman Split-Half Coefficient was 0,899. Hinkin (1995) stated that a alpha of 0,70 and above is typically sufficient. Kline (2010) also stated that reliability is excellent if it is above 0,90 and it is considered good if it is around 0,80 . As a result, it can be said that the validity and reliability of the TMMS including 20items and four-dimension adapted in the present study can be used to determine prospective teachers' moral metacognition. Based on the findings that we have summarized above, the instrument seems to offer a promising measurement to identify prospective teachers' moral metacognition. 


\section{REFERENCES}

Aikenhead, G. S. (1985). Collective decision making in the social context of science. Science Education, 69(4), 453-475.

Albright, J. J., \& Park, H. M. (2009). Confirmatory factor analysis using Amos, LISREL, Mplus, SAS/STAT CALIS. University Information Technology Services (UITS) Center for Statistical and Mathematical Computing Indiana University. Working Paper. http://www. indiana. edu/ statmath/stat/all/cfa/ind ex. html.

Arbuckle, J. L. (2005). AmosTM 6.0 user's guide. Amos Development Corporation.

Cassidy, E, W. \& Kurfman, D, G. (1977). Decision making as purpose and process, In Developing DecisionMaking Skills, Virginia: NCSS, 47th Yearbook.

Chong, W. H. (2007). The role of personal agency beliefs in academic self-regulation: An Asian perspective. School Psychology International, 28(1), 63-76.

Cohen, J. (1988). Statistical power analysis for the behavioral sciences (2nd ed.). Hillsdale, NJ: Erlbaum.

Çokluk, Ö., Şekercioğlu, G., \& Büyüköztürk, Ş. (2018). Sosyal bilimler için çok değişkenli istatistik: SPSS ve LISREL uygulamaları. Ankara: Pegem Akademi.

Dinsmore, D, L, Alexander, P, A, \& Loughlin, S, M. (2008). Focusing the conceptual lens on metacognition, self-regulation, and self-regulated learning, Educational Psychology Review, 20(4), 391-409.

Efklides, A. (2006). Metacognitive experiences: The missing link in the self-regulated learning process. Educational Psychology Review, 18(3), 287-291.

Fiske, S. T., \& Taylor, S. E. (1991). Social cognition (2nd ed.). New York, NY: McGraw-Hill.

Hannah, S, T, Avolio, B, F, \& May, D, R. (2011), Moral maturation and moral conation: A capacity approach to explaining moral thought and action, Academy of Management Review, 36, 663-685.

Heath, P. A., White, A. L., Berlin, D. F., \& Park, J. C. (1987). Decision making: Influence of features and presentation mode upon generation of alternatives. Journal of Research in Science Teaching, 24(9), 821-833.

Hinkin, T. R. (1995). A review of scale development practices in the study of organizations. Journal of management, 21(5), 967-988.

Hooper, D., Coughlan, J. and Mullen, M. (2008). Structural equation modeling: Guidelines for determining model fit. The Electronic Journal of Business Research Methods. 6 (1), 53-60.

Hu, L. T., \& Bentler, P. M. (1999). Cutoff criteria for fit indexes in covariance structure analysis: Conventional criteria versus new alternatives. Structural equation modeling: a multidisciplinary journal, 6(1), 1-55.

Jordan, J. (2009). A social cognition framework for examining moral awareness in managers and academics. Journal of Business Ethics, 84, 237-258.

Kline, R., B. (2010). Promise and pitfalls of structural equation modeling in gifted research. In: Thompson B, Subotnik RF, editors. Methodologies for conducting research on giftedness. Washington, DC, US: American Psychological Association, 147-69.

Kohlberg, L. (1963). The development of children's orientations toward a moral order: I. Sequence in the development of moral thought. Vita humana, 11-33.

Lajoie, S. P. (2008). Metacognition, self regulation, and self-regulated learning: A rose by any other name?. Educational Psychology Review, 20(4), 469-475.

McMahon, J, M.,\& Good, D, J, (2016). The moral metacognition scale: Development and validation, Ethics \& Behavior, 26(5), 357-394.

Narvaez, D. (2010). Moral complexity: The fatal attraction of truthiness and the importance of mature moral functioning, Perspectives on Psychological Science, 5(2), 163-181.

Oguz, N. (2001). Felsefi Yaklaşımların Işı̆̆̆ında Klinik Etiğe Giriş. Klinik Etik. İstanbul: Nobel, 9-25.

Rest, J. R. (1986). Moral development: Advances in research and theory. New York, NY: Praeger.

Ricco, R. B., \& Overton, W. F. (2011). Dual systems Competence $\longleftrightarrow-$ Procedural processing: A relational developmental systems approach to reasoning. Developmental Review, 31(2-3), 119-150. 
Sadler-Smith, E. (2012). Before virtue: Biology, brain, behavior, and the "moral sense", Business Ethics Quarterly, 22(2), 351-376.

Schermelleh-Engel, K., Moosbrugger, H., \& Müller, H. (2003). Evaluating the fit of structural equation models: Tests of significance and descriptive goodness-of-fit measures, Psychological Research, 8(2), 23-74.

Schraw, G., Crippen, K, J., \& Hartley, K. (2006). Promoting self-regulation in science education: Metacognition as part of a broader perspective on learning, Research in science education, 36(1-2), 111-139.

Schraw, G., \& Dennison, R. S. (1994). Assessing metacognitive awareness. Contemporary educational psychology, 19(4), 460-475.

Schunk, D. H. (2008). Metacognition, self-regulation, and self-regulated learning: Research recommendations. Educational psychology review, 20(4), 463-467.

Suhr, D. (2006). Exploratory or Confirmatory Factor Analysis. SAS Users Group International Conference (pp. 1 - 17). Cary: SAS Institute, Inc.

Tabachnick, B. G., Fidell, L. S., \& Ullman, J. B. (2007). Using multivariate statistics (Vol. 5). Boston, MA: Pearson.

Treviño, L. K., Weaver, G. R., \& Reynolds, S. J. (2006). Behavioral ethics in organizations: A review. Journal of management, 32(6), 951-990.

Zimmerman, B. J. (1989). A social cognitive view of self-regulated academic learning. Journal of educational psychology, 81(3), 329.

Zohar, A., \& Barzilai, S. (2013). A review of research on metacognition in science education: Current and future directions. Studies in Science Education, 49(2), 121-169. 